\title{
Exposure to Cocaine Regulates Inhibitory Synaptic Transmission in the Nucleus Accumbens
}

\author{
Mami Otaka, ${ }^{1 \star}$ Masago Ishikawa, ${ }^{1 \star}$ Brian R. Lee, ${ }^{3}$ Lei Liu, ${ }^{1}$ Peter A. Neumann, ${ }^{1}$ Ranji Cui, ${ }^{1}$ Yanhua H. Huang, ${ }^{2}$ \\ Oliver M. Schlüter, ${ }^{4}$ and Yan Dong ${ }^{1}$ \\ ${ }^{1}$ Department of Neuroscience and ${ }^{2}$ Department of Psychiatry, University of Pittsburgh, Pittsburgh, Pennsylvania 15260, ${ }^{3}$ Department of Molecular \\ Therapeutics, The Scripps Research Institute, Jupiter, Florida 33458, and ${ }^{4}$ Molecular Neurobiology and Cluster of Excellence "Nanoscale Microscopy and \\ Molecular Physiology of the Brain", European Neuroscience Institute, 37077 Göttingen, Germany
}

Medium spiny neurons (MSNs) within the nucleus accumbens shell (NAc) function to gate and prioritize emotional/motivational arousals for behavioral output. The neuronal output of NAc MSNs is mainly determined by the integration of membrane excitability and excitatory/inhibitory synaptic inputs. Whereas cocaine-induced alterations at excitatory synapses and membrane excitability have been extensively examined, the overall functional output of NAc MSNs following cocaine exposure is still poorly defined because little is known about whether inhibitory synaptic input to these neurons is affected by cocaine. Here, our results demonstrate multidimensional alterations at inhibitory synapses in NAc neurons following cocaine self-administration in rats. Specifically, the amplitude of miniature IPSCs (mIPSCs) was decreased after $21 \mathrm{~d}$ withdrawal from $5 \mathrm{~d}$ cocaine self-administration. Upon re-exposure to cocaine after $21 \mathrm{~d}$ withdrawal, whereas the amplitude of mIPSCs remained downregulated, the frequency became significantly higher. Furthermore, the reversal potential of IPSCs, which was not significantly altered during withdrawal, became more hyperpolarized upon cocaine re-exposure. Moreover, the relative weight of excitatory and inhibitory inputs to NAc MSNs was significantly decreased after $1 \mathrm{~d}$ cocaine withdrawal, increased after $21 \mathrm{~d}$ withdrawal, and returned to the basal level upon cocaine re-exposure after $21 \mathrm{~d}$ withdrawal. These results, together with previous results showing cocaine-induced adaptations at excitatory synapses and intrinsic membrane excitability of NAc MSNs, may provide a relatively thorough picture of the functional state of NAc MSNs following cocaine exposure.

\section{Introduction}

The nucleus accumbens shell (NAc) functions to gate emotional and motivational arousals for behavioral output (Mogenson and Huang, 1973; Mogenson et al., 1980). Exposure to cocaine and other drugs of abuse induces cellular adaptations in NAc medium spiny neurons (MSNs), and the resulting functional alterations of the NAc contribute to a variety of addiction-related emotional and motivational states (Wolf, 2010). Lacking apparent internal pacemaker mechanisms, NAc MSNs heavily rely on synaptic input to fire action potentials for their functional output (Wilson and Kawaguchi, 1996). Whereas synchronous excitatory synaptic input provides the major driving force to bring NAc MSNs to their functionally active state for action potential firing, inhibitory synaptic input makes NAc MSNs resistant to excitation (Wilson, 1986; O’Donnell and Grace, 1995; Wilson and Kawaguchi, 1996; Gambrill and Barria, 2011). Balanced in a finely tuned excitatory/inhibitory (E/I) synaptic integration,

\footnotetext{
Received Sept. 26, 2012; revised Feb. 8, 2013; accepted March 8, 2013.

Author contributions: M.O., M.I., Y.H., O.M.S., and Y.D. designed research; M.O., M.I., B.R.L., and L.L. performed research; M.O., M.I., P.A.N., and R.C. analyzed data; M.O., M.I., Y.H., O.M.S., and Y.D. wrote the paper.

This study was supported by the American Heart Association, the Humboldt Foundation, and National Institutes of Health-National Institute on Drug Abuse DA029565, DA028020, DA023206 and DA024570, and DA031551.

*M.O. and M.I. contributed equally to this work.

Correspondence should be addressed to Dr. Yan Dong, Department of Neuroscience, University of Pittsburgh, A210 Langley Hall/5th and Ruskin Avenues, Pittsburgh, PA 15260. E-mail: yandong@pitt.edu.

DOI:10.1523/JNEUROSCI.4577-12.2013

Copyright $\odot 2013$ the authors $\quad 0270-6474 / 13 / 336753-06 \$ 15.00 / 0$
}

NAc MSNs maintain a stable functional state. Thus, disrupting this E/I synaptic balance can be one way that exposure to cocaine reshapes the basal functional state of NAc MSNs. Although cocaine-induced alterations at excitatory synapses have been extensively examined, little is known about whether inhibitory synaptic input to NAc MSNs is affected following exposure to cocaine. Using contingent cocaine procedures, the present study examines the impact of cocaine exposure on IPSCs and their relative weight compared with excitatory synaptic input to NAc MSNs in rats.

\section{Materials and Methods}

Subjects. The subjects were 179 male Sprague Dawley rats (Simonsen; Harlan Laboratories), 30- to 40-d-old before surgery. Some rats were used at postnatal day 6 (P6) for controls (see Fig. 2). Rats were housed on a regular $12 \mathrm{~h}$ light/dark cycle (light on at 07:00 A.M.) with food and water available ad libitum.

Intravenous surgery. Rats were anesthetized with a xylazine-ketamine mixture $(5-10 / 50-100 \mathrm{mg} / \mathrm{kg}$, i.p.). The catheter was inserted into the jugular vein passed subcutaneously to the mid-scapula and connected to a harness with quick connect luer (SAI; Mu et al., 2010). The rats were then single housed and given 5-7 d to recover before the training session. After $5 \mathrm{~d}$ self-administration training $(>10$ infusion/2 h session/d at 0.75 $\mathrm{mg} / \mathrm{kg} /$ infusion for cocaine), animals were placed into their home cages for withdrawal. Catheters were flushed with sterile saline containing gentamicin $(5 \mathrm{mg} / \mathrm{ml})$ and heparin $(10 \mathrm{Us} / \mathrm{ml})$ every $24-48 \mathrm{~h}$ during recovery, training, and withdrawal. On withdrawal day 21 , a subgroup of rats was placed back into the operant boxes for cocaine 
re-exposure. The re-exposure procedure was identical to the $2 \mathrm{~h}$ self-administration session.

Apparatus. The self-administration chambers, controlled by a Med Associates system, had two nosepoke holes located $6 \mathrm{~cm}$ above the grid floor, but only one hole (active hole) activated the infusion pump. The luer on the harness was connected to a liquid swivel with dual-luer spring tether and connected to the syringe of the infusion pump. Poking in the other hole (inactive hole) was also recorded. A nosepoke to the active hole resulted in a cocaine infusion, accompanied by the switch-on of a light as a conditioned stimulus (CS) and a background light. The CS stayed on for $6 \mathrm{~s}$, and the background light for $20 \mathrm{~s}$. During this $20 \mathrm{~s}$, additional nosepokes were counted but did not result in cocaine infusion.

Preparation of acute brain slices. Rats were decapitated following isoflurane anesthesia. Coronal slices $(250-300 \mu \mathrm{m})$ containing the NAc were prepared on a VT1200S vibratome (Leica) in $4^{\circ} \mathrm{C}$ cutting solution containing the following (in $\mathrm{mm}$ ): $135 \mathrm{~N}$-methyl-Dglucamine, $1 \mathrm{KCl}, 1.2 \mathrm{KH}_{2} \mathrm{PO}_{4}, 0.5 \mathrm{CaCl}_{2}, 1.5$ $\mathrm{MgCl}_{2}, 20$ choline- $\mathrm{HCO}_{3}$, and 11 glucose, saturated with $95 \% \mathrm{O}_{2} / 5 \% \mathrm{CO}_{2}$, $\mathrm{pH}$ adjusted to 7.4 with $\mathrm{HCl}$. Slices were incubated in artificial CSF (aCSF) containing the following (in mM): $119 \mathrm{NaCl}, 2.5 \mathrm{KCl}, 2.5 \mathrm{CaCl}_{2}, 1.3$ $\mathrm{MgCl}_{2}, 1 \mathrm{NaH}_{2} \mathrm{PO}_{4}, 26.2 \mathrm{NaHCO}_{3}$, and 11 glucose, saturated with $95 \% \mathrm{O}_{2} / 5 \% \mathrm{CO}_{2}$ at $37^{\circ} \mathrm{C}$ for $30 \mathrm{~min}$ and then allowed to recover for $>30 \mathrm{~min}$ at room temperature before experimentation.

Electrophysiological recordings. All recordings were made from MSNs located in the NAc shell. During recordings, slices were superfused with aCSF that was heated to $31-33^{\circ} \mathrm{C}$ by passing the solution through a feedbackcontrolled in-line heater (Warner) before entering the chamber. Recordings were made under visual guidance ( 40 or $60 \times$, differential interference contrast optics) with electrodes (2-5 M 2 ) filled with the following (in mM): 140 $\mathrm{CsCH}_{3} \mathrm{O}_{3} \mathrm{~S}$ (or $\mathrm{CsCl}$ for recording mIPSCs), 5 TEA-Cl, 0.4 Cs-EGTA, 20 HEPES, 2.5 Mg-ATP, $0.25 \mathrm{Na}-\mathrm{GTP}$, and 1 QX-314, pH 7.3. Picrotoxin (100 $\mu \mathrm{M}$ ) (or APV, $50 \mu \mathrm{M}$ ) was included in the external perfusion aCSF to block $\mathrm{GABA}_{\mathrm{A}}$ (or NMDA receptors; NMDAR).

For gramicidin-perforated patch, micropipettes were filled with an internal solution (100 mM KCl and $10 \mathrm{~mm}$ HEPES, pH 7.2) and the same solution, which contains $40 \mu \mathrm{g} / \mu \mathrm{l}$ gramicidin. IPSCs were recorded in the presence of APV $(50 \mu \mathrm{M})$ and NBQX $(2 \mu \mathrm{M})$ in standard.

To measure input-output efficacy, a combined excitatory and inhibitory input was evoked in each recorded NAc MSN by a stimulation electrode. The distance $(100 \mu \mathrm{m})$, stimulation duration $(0.25 \mathrm{~ms})$, stimulation electrode size (2.5-3 M $\Omega$ ), and stimulation frequency (20 $\mathrm{Hz}$ ) were fixed for all recordings. Micropipettes were filled with a potassium-based internal solution containing the following (in $\mathrm{mM}$ ): 130 $\mathrm{KMeSO}_{3}, 10 \mathrm{KCl}, 0.4 \mathrm{EGTA}, 10 \mathrm{HEPES}, 2.5 \mathrm{Mg}$-ATP, $0.25 \mathrm{Na}$-GTP, and $2 \mathrm{MgCl}_{2}-6 \mathrm{H}_{2} \mathrm{O}, \mathrm{pH}$ 7.3. The stimulation intensity continuously increased by an increment of $2 \mu \mathrm{A}$.

Presynaptic afferents were stimulated by a constant-current isolated stimulator (Digitimer), using a monopolar electrode (glass pipette filled with aCSF). Stimulus strength was adjusted so that the first EPSC/IPSC was between 100 and $500 \mathrm{pA}$. Trains of pulses were generated using Clampex software (Molecular Devices). Series resistance was 9-20 $\mathrm{M} \Omega$, uncompensated, and monitored continuously during recording. Cells with a change in series resistance beyond $15 \%$ were not accepted for data analysis. Synaptic currents were recorded with a MultiClamp 700B
B

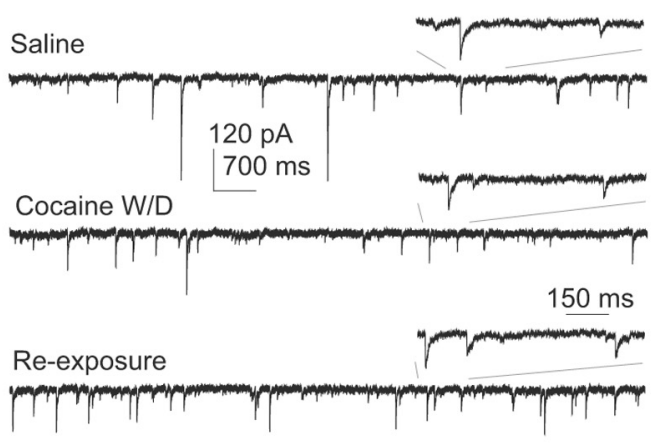

D

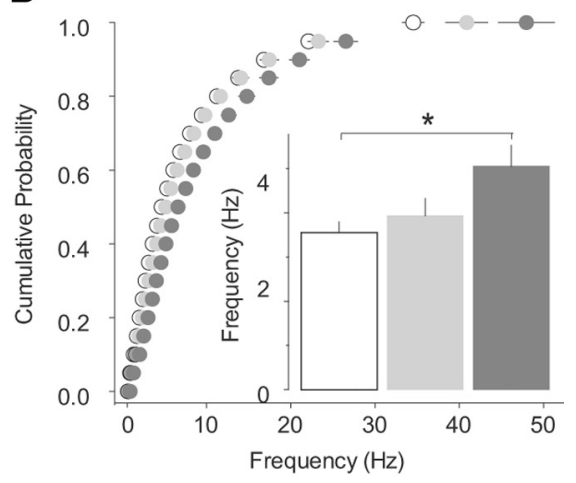

Figure 1. Regulation of mIPSCs in NAc MSNs after cocaine self-administration. $\boldsymbol{A}$, Summarized results showing a $5 \mathrm{~d}$ cocaine

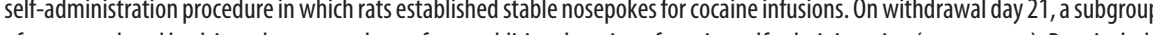
Summarized results showing that the frequency of mIPSCs was not affected after cocaine withdrawal but was increased upon re-exposure to cocaine after withdrawal. ${ }^{*} p<0.05$.

amplifier, filtered at $2.6-3 \mathrm{kHz}$, amplified five times, and then digitized at $20 \mathrm{kHz}$.

Drugs. Tetrodotoxin, D-APV, and NBQX were purchased from Tocris Bioscience. Picrotoxin, gramicidin, and all other chemicals were purchased from Sigma-Aldrich.

Data acquisition and statistics. All data were analyzed off-line. mIPSCs were obtained at least 10 min after achieving whole-cell configuration. For analysis, a template was made by averaging $\sim 100$ hand-picked miniature events using pClamp10 software. Relative AMPA receptors (AMPAR)/NMDAR and AMPAR/GABA receptor (GABAR) ratios were calculated by normalizing the amplitude of the total control response to 1. All statistical results were expressed as mean \pm SEM. Two-tail $t$ test or ANOVA was used for statistical comparisons as specified in the text.

\section{Results}

This study focused on MSNs within the ventrolateral NAc shell, a brain site that has been implicated in emotional and motivational responses (Kelley, 2004). To examine potential cocaine-induced adaptations at inhibitory synapses of NAc neurons, we used a 5-d cocaine self-administration procedure (Mu et al., 2010), in which rats nosepoked for intravenous injection of cocaine (Fig. 1A). After $1 \mathrm{~d}$ or $21 \mathrm{~d}$ withdrawal, rats were either killed or placed back to the operant boxes for another $2 \mathrm{~h}$ session (i.e., re-exposure) and then killed immediately for slice electrophysiology.

We first recorded mIPSCs from NAc MSNs. Our results show that the amplitude of mIPSCs was decreased after $21 \mathrm{~d}$ with- 
A P6

P30
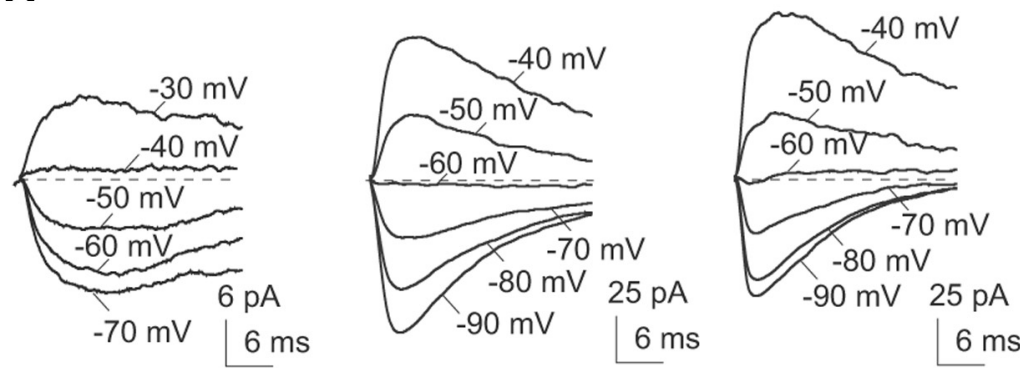

B

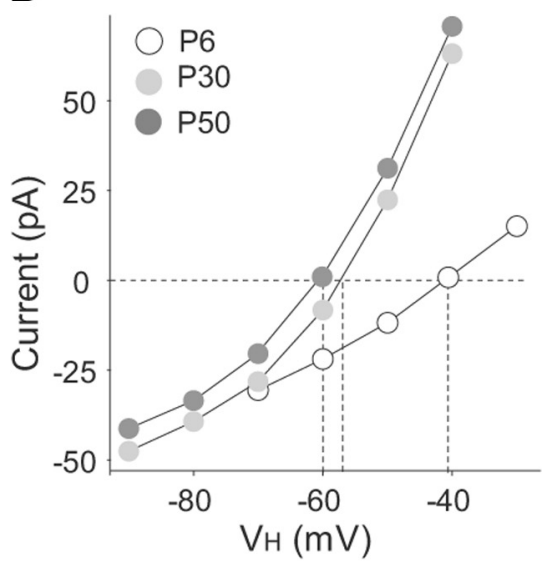

C

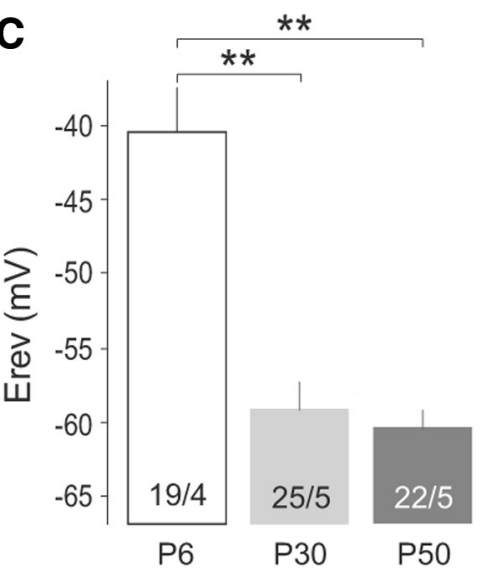

D saline: $5 d+21 d$ wd cocaine: $5 d+21 d$ wd
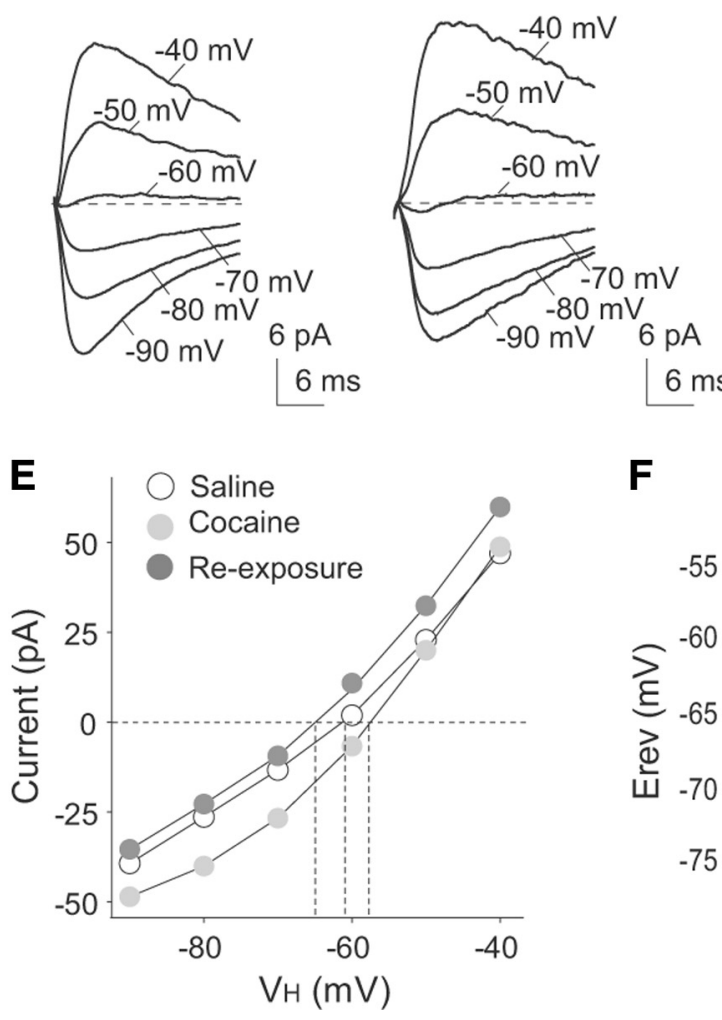

$\mathbf{F}$

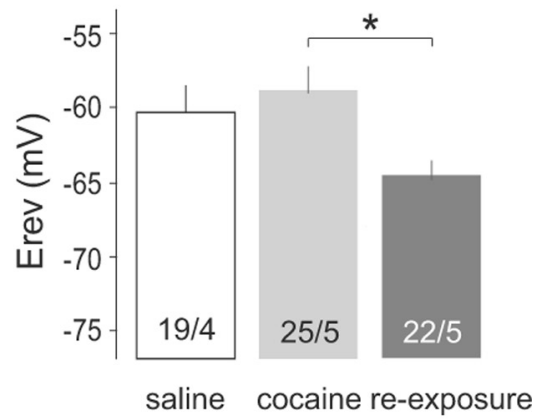

Figure 2. Re-exposure to cocaine after withdrawal hyperpolarizes the reversal potential of IPSCs in NAc MSNs. $A$, Example IPSCS elicited at different membrane potentials in NAC MSNs from rats at ages P6, P30, and P50. Recording made via perforated patch electrode. $\boldsymbol{B}$, The $I-V$ curves of IPSCs in NAc MSNs from different ages of rats. $\boldsymbol{C}$, Summarized results showing different reversal potentials of IPSCs in NAc MSNs can be detected from different ages of rats. $\boldsymbol{D}$, Example IPSCs elicited at different membrane drawal from cocaine self-administration, and this decrease was not affected by cocaine re-exposure $\left(F_{(2,63)}=4.230, p<\right.$ 0.05 , one-way ANOVA; $p<0.05$, saline vs cocaine and saline vs re-exposure, $p=$ 1.00 , cocaine vs re-exposure, Bonferroni post-tests; Fig. $1 B, C$ ). Furthermore, the frequency of mIPSCs was not affected after cocaine withdrawal but was significantly increased upon cocaine re-exposure $\left(F_{(2,63)}=\right.$ $3.719, p<0.05$, one-way ANOVA; $p=1.00$, saline vs cocaine; $p<0.05$, saline vs re-exposure; $p=0.132$, cocaine vs re-exposure, Bonferroni post-tests; Fig. $1 B, D)$. In general, alterations in the amplitude and frequency of miniature events reflect postsynaptic and presynaptic changes, respectively. Thus, these results suggest a decrease in postsynaptic responsiveness of GABAergic synapses in NAc MSNs after cocaine withdrawal and this adaptive change was not affected upon cocaine re-exposure, whereas presynaptic release was not altered after cocaine withdrawal but enhanced upon re-exposure to cocaine. Apparently, these presynaptic and postsynaptic changes functionally oppose to each other.

Although GABAergic synaptic transmission is normally inhibitory, the inhibitory efficacy is determined by its reversal potential. Typically, the more hyperpolarized the reversal potential from the resting membrane potential, the more inhibitory control it can provide. Using a perforated patch, we next examined whether cocaine self-administration affected the reversal potential of IPSCs in NAc MSNs. To validate the experimental procedure, we used the perforated patch to measure the reversal potential of IPSCs in NAc MSNs from rats with different ages. Our results show that the reversal potential of IPSCs in NAc MSNs was substantially more depolarized in young rats $(\mathrm{P} 6)$ than older rats (postnatal days 30 or 50$)\left(F_{(2,28)}=30.680, p<\right.$ 0.001 , one-way ANOVA; $p<0.001$, P6 vs $\mathrm{P} 30$ and $\mathrm{P} 6$ vs P50; $p=1.00, \mathrm{P} 30$ vs P50, Bonferroni post-tests; Fig. $2 A-C$ ), consistent with the general properties of GABAergic synapses during development (Ben-Ari et al., 1989). Thus, our experi-

\footnotetext{
$\leftarrow$

potentials from rats with saline self-administration and $21 \mathrm{~d}$ withdrawal; rats with cocaine self-administration and $21 \mathrm{~d}$ withdrawal; and rats with cocaine self-administration, $21 \mathrm{~d}$ withdrawal, and re-exposure to cocaine on withdrawal day 21. $\boldsymbol{E}$, The I-V curves of IPSC s in NAc MSNs from rats with different drug administration procedures. $\boldsymbol{F}$, Summarized results showing that the reversal potential of IPSCs in NAc MSNs was not affected after withdrawal from cocaine self-administration but became hyperpolarized upon re-exposure to cocaine after withdrawal. ${ }^{*} p<$ $0.05 ;{ }^{* *} p<0.01$
} 
A saline: $5 d+21 d$ wd $\quad$ cocaine: $5 d+21 d$ wd

cocaine: $5 d+21 d$ wd + re-exposure
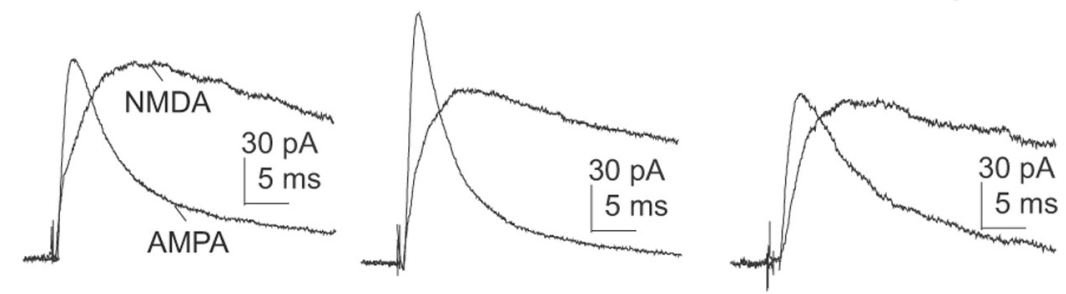

B

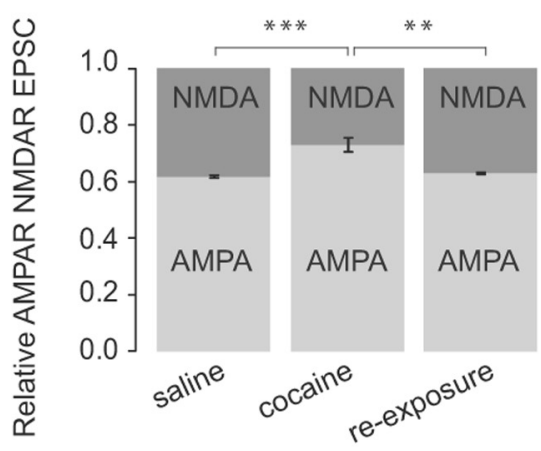

C

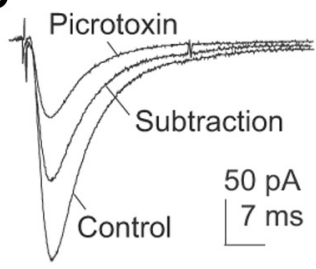

saline $1 \mathrm{~d}$ wd

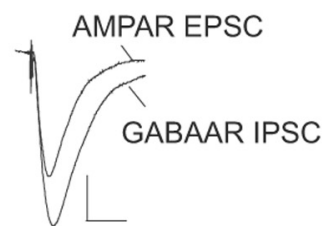

cocaine $1 \mathrm{~d}$ wd

saline $21 d$ wd

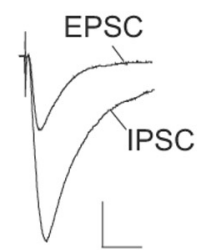

cocaine $21 \mathrm{~d}$ wd
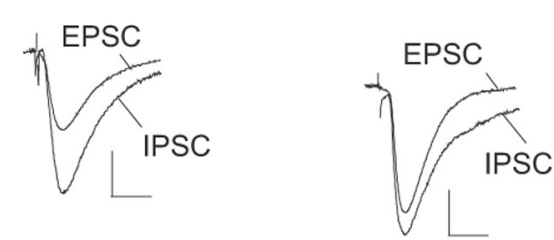

cocaine $21 \mathrm{~d}$ wd

+ re-exposure

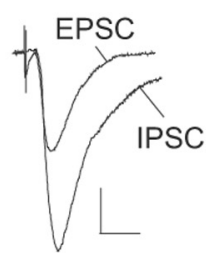

D

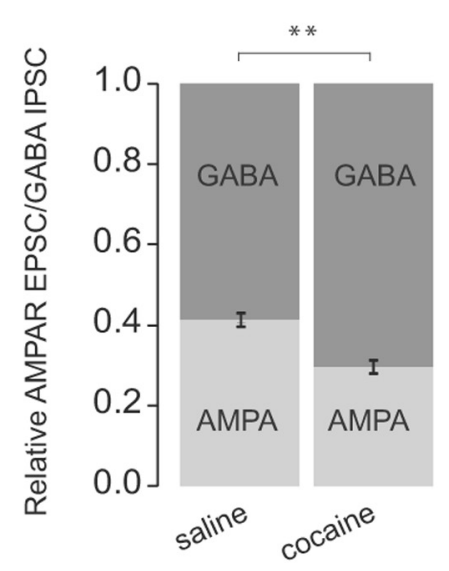

$21 \mathrm{~d}$ withdrawal

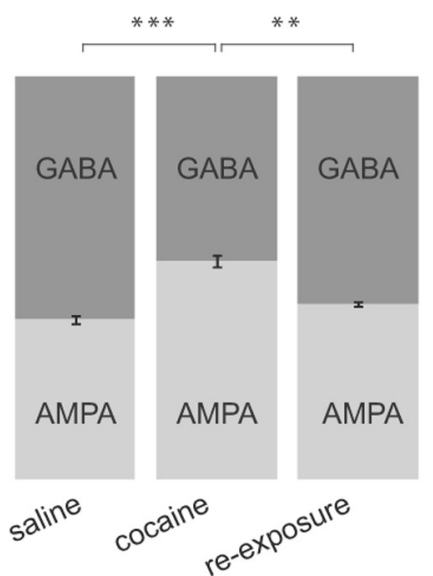

Figure 3. The AMPAR/NMDAR and AMPAR/GABAR ratios in NAC MSNs are dynamically regulated after cocaine selfadministration. $A$, Example AMPAR and NMDAR EPSCs in NAc MSNs from rats with saline self-administration and $21 \mathrm{~d}$ withdrawal; rats with cocaine self-administration and $21 \mathrm{~d}$ withdrawal; and rats with cocaine self-administration, $21 \mathrm{~d}$ withdrawal, and

mental setup can detect potential alterations in the reversal potential of IPSCs.

Using the same procedure, we measured the reversal potential of IPSCs in NAc MSNs from rats trained with cocaine self-administration (Fig. 2D). Our results show that the reversal potential of IPSCs in NAc MSNs was not affected after $21 \mathrm{~d}$ withdrawal from cocaine but became significantly hyperpolarized upon cocaine re-exposure $\left(F_{(2,63)}=3.605, p<0.05\right.$, one-way ANOVA; $p<0.05$, cocaine vs re-exposure, $p=0.21$, saline vs re-exposure; Bonferroni post-tests; Fig. 2E,F). This cocaine-induced change may provide stronger inhibitory control from GABAergic synapses to dampen the excitation of NAc MSNs after re-exposure to cocaine.

Because NAc MSNs do not possess intrinsic pace-making mechanisms, the functional output is critically dependent on the integration of excitatory and inhibitory synaptic inputs. We next examined whether the balance between E/I synaptic inputs was affected by cocaine self-administration. Consistent with cocaine-induced alterations at excitatory synapses in NAc MSNs following passive procedures of cocaine injections (Kourrich et al., 2007), we observed an increase in the ratio of AMPAR- and NMDAR-mediated EPSCs in NAc MSNs after withdrawal from cocaine self-administration, and this AMPAR/NMDAR ratio returned to the basal level upon cocaine re-exposure $\left(F_{(2,12)}=16.51, p<0.001\right.$, one-way ANOVA; $p<0.01$, saline vs cocaine and cocaine vs re-exposure; $p=1.00$, saline vs reexposure, Bonferroni post-tests; Fig. $3 A, B$ ). This result, together with previous biochemical studies measuring surface AMPAR subunits (Conrad et al., 2008; Wolf, 2010), suggests that the excitatory

\footnotetext{
$\leftarrow$

re-exposure to cocaine after withdrawal. $\boldsymbol{B}$, Summarized results showing that the AMPAR/NMDAR ratio was increased after long-term withdrawal from cocaine self-administration, but this withdrawal effect was abolished upon cocaine reexposure. C, Example traces showing IPSCS and EPSCs in the same NAc MSNs from rats with 1 or $21 \mathrm{~d}$ withdrawal from saline or cocaine self-administration, or with a re-exposure to cocaine after $21 \mathrm{~d}$ withdrawal. The upper left traces show pharmacological isolation of IPSCS and EPSCS. Briefly, total (control) synaptic currents were recorded from NAc MSNs containing both IPSCS and EPSCS. Perfusion of picrotoxin selectively inhibited IPSCS. EPSCS were obtained by subtracting picrotoxin-sensitive currents from the total currents. $D$, Summarized results showing that the AMPAR/GABAR ratio was significantly decreased after $1 \mathrm{~d}$ withdrawal from cocaine selfadministration but increased after $21 \mathrm{~d}$ withdrawal, and this change was abolished upon re-exposure to cocaine. ${ }^{* *} p<$ $0.01 ; * * * 0.001$.
} 

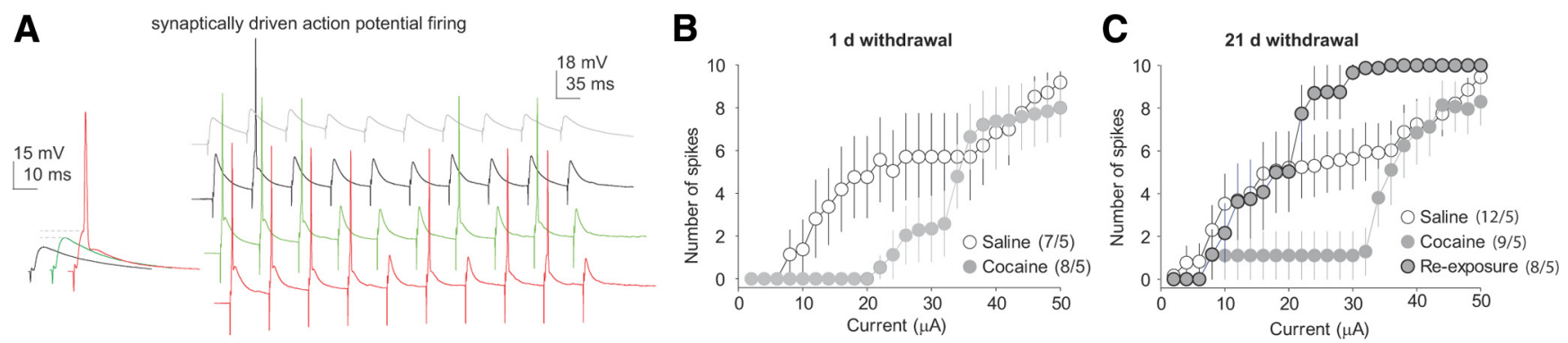

Figure 4. Synaptically driven action potential firing is dynamically regulated after cocaine self-administration. $A$, Example traces of synaptically driven action potential firing in an NAc MSN. Left, Voltage traces from an example NAc MSN show that the synaptically driven depolarization of membrane potential increased in response to increased intensity of stimulations (12, 14 , and $16 \mu \mathrm{A})$. Note that the stimulation artifacts preceded the synaptically driven membrane depolarization and action potentials, suggesting they were synaptically evoked events. Right, Voltage traces from an example NAc MSN show synaptically driven action potential firings (stimulation intensity, 12, 18, 24, and $32 \mu \mathrm{A}$ ). $\boldsymbol{B}$, Summarized results showing that after $1 \mathrm{~d}$ withdrawal from cocaine self-administration the input- output efficacy was significantly decreased in NAc MSNs. Note that the decrease became minimal when the synaptic stimulations were strong (right part of the curve). C, Summarized results showing that after $21 \mathrm{~d}$ withdrawal from cocaine self-administration, the input- output efficacy of NAc MSNs remained low upon relatively weak synaptic activations (left part of the curve), and re-exposure to cocaine instantly increased the input- output efficacy beyond the basal (saline control) level during relatively strong synaptic activations (right part of the curve).

synaptic strength was increased after withdrawal but returned to the basal level upon cocaine re-exposure following cocaine self-administration.

To examine the effect of cocaine on the E/I in NAc MSNs, we measured the relative weight of excitatory and inhibitory synaptic inputs. Briefly, we randomly placed a stimulation electrode within the NAc slice to elicit a compound current in NAc MSNs, containing both EPSC and IPSC (Fig. $3 C$ ). We then perfused the slice with picrotoxin $(0.1 \mathrm{~mm})$ to selectively inhibited IPSCs (Fig. $3 C)$. By subtracting the picrotoxin-sensitive current from the total current, we obtained EPSCs (Fig. 3C), which was sensitive to AMPAR-selective antagonist NBQX (data not shown). The E/I was thus operationally defined as the ratio of the peak amplitude of EPSCs divided by the peak amplitude of IPSCs. The E/I was significantly decreased after $1 \mathrm{~d}$ withdrawal from cocaine selfadministration $\left(t_{(8)}=4.65, p<0.01\right.$, saline vs cocaine $)$, but increased after $21 \mathrm{~d}$ withdrawal, and returned to the basal level upon cocaine re-exposure after withdrawal $\left(F_{(2,12)}=49.25, p<\right.$ 0.0001 , one-way ANOVA; $p<0.001$, saline vs cocaine and cocaine vs re-exposure; $p=0.08$, saline vs re-exposure, Bonferroni post-tests; Fig. $3 C, D$ ). Thus, the net change of the E/I in NAc MSNs is dynamic following cocaine self-administration.

Our present findings together with previous results demonstrate dynamic alterations of the membrane excitability and E/I in the NA during cocaine withdrawal and upon re-exposure to cocaine after withdrawal. In an attempt to determine the integrated effect of these alterations on the overall functional output of NAc MSNs, we examined the input-output efficacy by measuring synaptically driven action potential firing in NAc MSNs (Hopf et al., 2003). Specifically, a combined excitatory and inhibitory input was evoked in each recorded NAc MSN by a stimulation electrode (see Materials and Methods). Net depolarizing synaptic potentials (a combination of EPSPs and IPSPs) were observed upon these stimulations, and action potentials were evoked when the synaptically driven depolarization drove the membrane potential beyond the threshold of action potentials (Fig. 4A) (Hopf et al., 2003). After 1 d withdrawal from cocaine selfadministration, the input-output efficacy was significantly decreased $\left(F_{(49,637)}=1.80, p=0.001\right.$; Fig. $\left.4 B\right)$. The inputoutput efficacy remained low after $21 \mathrm{~d}$ withdrawal but was significantly increased after re-exposure to cocaine after $21 \mathrm{~d}$ withdrawal $\left(F_{(98,1274)}=3.44, p<0.001\right.$, saline vs cocaine; $p<$ 0.01 cocaine vs re-exposure; two-factor ANOVA with Bonferroni post-tests; Fig. $4 C$ ).

\section{Discussion}

By measuring different aspects of GABAergic synaptic input, our present study is among the first showing dynamic changes at inhibitory synapses in the NAc following cocaine selfadministration. These results may help generate an overall picture of the functional alterations of NAc MSNs during drug withdrawal and relapse.

\section{Withdrawal}

After $1 \mathrm{~d}$ withdrawal from cocaine self-administration, the E/I ratio was significantly decreased (Fig. $3 D$ ), which can be partially mediated by the reduced excitatory synaptic strength (Wolf, 2010). These synaptic adaptations together with cocaine-induced decreases in the membrane excitability ( $\mathrm{Mu}$ et al., 2010) may contribute to the decreased input-output efficacy (Fig. 4B). Thus, the overall functional output of NAc MSNs is likely to be decreased after short-term cocaine withdrawal. After $21 \mathrm{~d}$ withdrawal, the input-output efficacy remained low (Fig. 4C). At this time point, the postsynaptic responsiveness of GABAergic synapses in NAc MSNs appears to be reduced (Fig. 1C), whereas the excitatory synaptic input appears to be enhanced both presynaptically (Suska et al., 2013) and postsynaptically (Conrad et al., 2008; Wolf, 2010) (Fig. 3). These synaptic adaptations may together contribute to the increased E/I ratio observed in NAc MSNs at this withdrawal time point (Fig. 3D), and these synaptic adaptations function to promote the excitation of NAc MSNs. On the other hand, the intrinsic membrane excitability of NAc MSNs returns close to the saline control level, but a minimal decrease still remains (Mu et al., 2010). A decreased input-output efficacy (Fig. 4C) thus suggests that the cocaine-induced membrane adaptation, although small, predominates and decreases the overall functional output of NAc MSNs.

It is important to note that the above cellular changes were detected in the condition that E/I inputs are experimentally normalized. That is, upon the same synaptic input, NAc MSNs would respond less actively after cocaine withdrawal. However, excitation of NAc MSNs in vivo relies on synaptic inputs. As such, even if NAc MSNs are set to be less responsive, their excitation state can still be high in behaving animals if there is increased excitatory input.

\section{Re-exposure}

Upon re-exposure to cocaine, the presynaptic potentiation (Fig. $1 D)$ combined with the hyperpolarized reversal potential may 
effectively enhance inhibitory synaptic input to NAc MSNs. At the same time, the withdrawal-induced upregulation of excitatory synaptic strength may transiently decrease to the basal level (i.e., saline control). These synaptic changes integrate, potentially leading to the return of E/I ratio to the basal (control) level (Fig. $3 D$ ). On the other hand, the intrinsic membrane excitability of NAc MSNs is substantially increased upon re-exposure to cocaine (Mu et al., 2010). This membrane change may predominate in synapse-membrane integration, resulting in an increase in the input-output efficacy of NAc MSNs, especially upon strong synaptic input (Fig. 4C).

\section{GABAergic synapses in the NAc}

Compared with cocaine-induced adaptations at excitatory synapses and in the membrane excitability, much less is understood about how cocaine exposure affects inhibitory synaptic transmission in the NAc. However, the available results suggest that contingent and noncontingent cocaine procedures produce opposite effects on GABAergic transmission in the NAc. Using a noncontingent repeated procedure, Kalivas et al. demonstrate that the basal (ambient) levels of GABA in the NAc are increased after 3 week withdrawal from cocaine administration (Xi et al., 2003). This withdrawal-associated upregulation may result from the potential hyperactivity of fast-spiking interneurons (FSIs); our recent results indicate that the membrane excitability of $\mathrm{CB} 1$ expressing FSIs within the NAc shell is increased after withdrawal from cocaine exposure, which may lead to increased release of GABA (Winters et al., 2012). On the other hand, a decreased level of GABA in the NAc is observed after extinction from cocaine self-administration (Miguéns et al., 2011). Thus, GABAergic synaptic transmission in the NAc might be one of the neural substrates that differentiates the cellular and behavioral effects of contingent and noncontingent cocaine procedures.

\section{Conclusion and future direction}

NAc MSNs are highly heterogeneous and can be divided into different subpopulations. For example, based on receptor/transmitter subtypes, the NAc neurons can be divided into three subpopulations, one coexpressing dopamine D1 receptors and substance $\mathrm{P}$, one coexpressing dopamine D2 receptors and enkephalin, and one expressing both D1 and D2 receptors (Le Moine and Bloch, 1995; Gong et al., 2003; Lee et al., 2006). Based on electrophysiological properties, NAc neurons can be categorized as neurons with or without gap junctions with their neighboring NAc neurons (O'Donnell and Grace, 1993). Thus, a key future direction would be to determine whether these identified cocaine-induced adaptations are cross-board effects or only occur in one subtype of neurons. Nonetheless, our present results indicate that GABAergic transmission undergoes dynamic alterations after withdrawal from cocaine self-administration and upon re-exposure to cocaine. These adaptive changes may contribute to the pathophysiological functional output of NAc neurons and NAc-based behaviors observed in cocaine-exposed subjects.

\section{References}

Ben-Ari Y, Cherubini E, Corradetti R, Gaiarsa JL (1989) Giant synaptic potentials in immature rat CA3 hippocampal neurones. J Physiol 416:303325. Medline

Conrad KL, Tseng KY, Uejima JL, Reimers JM, Heng LJ, Shaham Y, Marinelli
M, Wolf ME (2008) Formation of accumbens GluR2-lacking AMPA receptors mediates incubation of cocaine craving. Nature 454:118-121. CrossRef Medline

Gambrill AC, Barria A (2011) NMDA receptor subunit composition controls synaptogenesis and synapse stabilization. Proc Natl Acad Sci U S A 108:5855-5860. CrossRef Medline

Gong S, Zheng C, Doughty ML, Losos K, Didkovsky N, Schambra UB, Nowak NJ, Joyner A, Leblanc G, Hatten ME, Heintz N (2003) A gene expression atlas of the central nervous system based on bacterial artificial chromosomes. Nature 425:917-925. CrossRef Medline

Hopf FW, Cascini MG, Gordon AS, Diamond I, Bonci A (2003) Cooperative activation of dopamine $\mathrm{D} 1$ and $\mathrm{D} 2$ receptors increases spike firing of nucleus accumbens neurons via G-protein betagamma subunits. J Neurosci 23:5079-5087. Medline

Kelley AE (2004) Ventral striatal control of appetitive motivation: role in ingestive behavior and reward-related learning. Neurosci Biobehav Rev 27:765-776. CrossRef Medline

Kourrich S, Rothwell PE, Klug JR, Thomas MJ (2007) Cocaine experience controls bidirectional synaptic plasticity in the nucleus accumbens. J Neurosci 27:7921-7928. CrossRef Medline

Lee KW, Kim Y, Kim AM, Helmin K, Nairn AC, Greengard P (2006) Cocaine-induced dendritic spine formation in D1 and D2 dopamine receptor-containing medium spiny neurons in nucleus accumbens. Proc Natl Acad Sci U S A 103:3399-3404. CrossRef Medline

Le Moine C, Bloch B (1995) D1 and D2 dopamine receptor gene expression in the rat striatum: sensitive cRNA probes demonstrate prominent segregation of D1 and D2 mRNAs in distinct neuronal populations of the dorsal and ventral striatum. J Comp Neurol 355:418-426. CrossRef Medline

Miguéns M, Botreau F, Olias O, Del Olmo N, Coria SM, Higuera-Matas A, Ambrosio E (2011) Genetic differences in the modulation of accumbal glutamate and gamma-amino butyric acid levels after cocaineinduced reinstatement. Addict Biol. Advance online publication. Retrieved Oct. 18, 2011. doi:10.1111/j.1369-1600.2011.00404.x. CrossRef

Mogenson GJ, Huang YH (1973) The neurobiology of motivated behavior. Prog Neurobiol 1:55-83. Medline

Mogenson GJ, Jones DL, Yim CY (1980) From motivation to action: functional interface between the limbic system and the motor system. Prog Neurobiol 14:69-97. CrossRef Medline

Mu P, Moyer JT, Ishikawa M, Zhang Y, Panksepp J, Sorg BA, Schlüter OM, Dong Y (2010) Exposure to cocaine dynamically regulates the intrinsic membrane excitability of nucleus accumbens neurons. J Neurosci 30 : 3689-3699. CrossRef Medline

O’Donnell P, Grace AA (1993) Dopaminergic modulation of dye coupling between neurons in the core and shell regions of the nucleus accumbens. J Neurosci 13:3456-3471. Medline

O’Donnell P, Grace AA (1995) Synaptic interactions among excitatory afferents to nucleus accumbens neurons: hippocampal gating of prefrontal cortical input. J Neurosci 15:3622-3639. Medline

Suska A, Lee BR, Huang YH, Dong Y, Schlüter OM (2013) Selective presynaptic enhancement of the prefrontal cortex to nucleus accumbens pathway by cocaine. Proc Natl Acad Sci U S A 110:713-718. CrossRef Medline

Wilson CJ (1986) Postsynaptic potentials evoked in spiny neostriatal projection neurons by stimulation of ipsilateral and contralateral neocortex. Brain Res 367:201-213. CrossRef Medline

Wilson CJ, Kawaguchi Y (1996) The origins of two-state spontaneous membrane potential fluctuations of neostriatal spiny neurons. J Neurosci 16: 2397-2410. Medline

Winters BD, Krüger JM, Huang X, Gallaher ZR, Ishikawa M, Czaja K, Krueger JM, Huang YH, Schlüter OM, Dong Y (2012) Cannabinoid receptor 1-expressing neurons in the nucleus accumbens. Proc Natl Acad Sci U S A 109:E2717-2725. CrossRef Medline

Wolf ME (2010) The Bermuda Triangle of cocaine-induced neuroadaptations. Trends Neurosci 33:391-398. CrossRef Medline

Xi ZX, Ramamoorthy S, Shen H, Lake R, Samuvel DJ, Kalivas PW (2003) GABA transmission in the nucleus accumbens is altered after withdrawal from repeated cocaine. J Neurosci 23:3498-3505. Medline 